\title{
ENERGY INCREASE BY USE OF A 2-PARAMETER RULE CURVE FOR HYDROPOWER GENERATION
}

\author{
HORACIO L. VELASCO \\ Director, CALTEC, S.C.
}

\begin{abstract}
A new 2-Parameter Rule Curve (patent pending) for Hydropower Generation takes into account the current state of the system, represented by the beginning-of-month reservoir level, in the selection of the end-of-month Rule Curve level/storage. Thus, the two decision parameters are current time and reservoir level. The Rule Curve aims to preserve the firm energy, and to generate as much secondary energy as possible; and is based on the maximum monthly value of a composite parameter related to the variation of the potential energy stored in the reservoir, calculated for every month in the backward simulation that gives the Firm Energy Yield of the reservoir-power plant system. The Rule Curve levels are calculated to give the required end-of-month level for each month as a function of the beginningof-month level, can be represented in tabular (matrix) and graphical forms, and can be used alone or combined with the Rule Curve proposed by the USACE (1985 and 1989), whose only parameter is current time. The use of this new 2-Parameter Rule Curve for single reservoirs can increase the annual average/secondary energy output without reducing the firm energy, as tested by the simulation of several hydropower developments; the results show an increase of average/secondary energy when compared with the USACE Rule Curve. Energy increase depends on net head variability, regulating capacity of the reservoir and power-plant-rated capacity. A 50-year simulation of Grand Coulee Dam gives an average energy output of $22.6 \mathrm{TW}-\mathrm{h} /$ year with the 2-Parameter Rule Curve, and 20.9 TW-h/ year with the USACE Rule Curve. The increase in average/secondary energy is $1.7 \mathrm{TW}-\mathrm{h} /$ year, due only to the change of the Rule Curve. Data published by the USBR indicates an average output of 21 TW-h/year for Grand Coulee Dam, which confirms the simulated results.

Keywords: hydropower, potential energy, reservoirs, rule curve, simulation.
\end{abstract}

\section{INTRODUCTION}

Many studies on planning and operation of reservoirs for power production rely on the operational strategy stated by the USACE in reference [1], which aims to preserve the Firm Energy of the reservoir and then to produce secondary energy. The strategy presented in [1] is based on two aspects: (a) the actual control strategy and (b) a set of control values of the reservoir level, which acts as a threshold in the decision-making process, and is called the Rule Curve. This Rule Curve has one parameter, which is the current month (it is a 1-parameter set), and gives a control value of the reservoir level at the end of each calendar month. The operational strategy is the following: (i) for the current month simulate the operation of the reservoir/ powerhouse generating only the continuous power and firm energy; (ii) if the simulated endof-month level in the reservoir falls below the control value, generate only the firm energy and continuous power; (iii) if the simulated end-of-month level is greater than the control value, generate as much energy as possible until the level reaches down to the control value, always limited by the power-plant capacity.

The Rule Curve and the continuous power/firm energy yield are obtained by a recursive backwards simulation algorithm until the maximum firm yield and continuous power are obtained. The calculation of the continuous power/firm energy yield is made by trial-anderror, generating only the trial continuous power, and calculating the required level at the beginning of each time period. The initial condition is the reservoir at the minimum pool level at the end of the time series; the reservoir fails if it requires a level greater than the maximum 


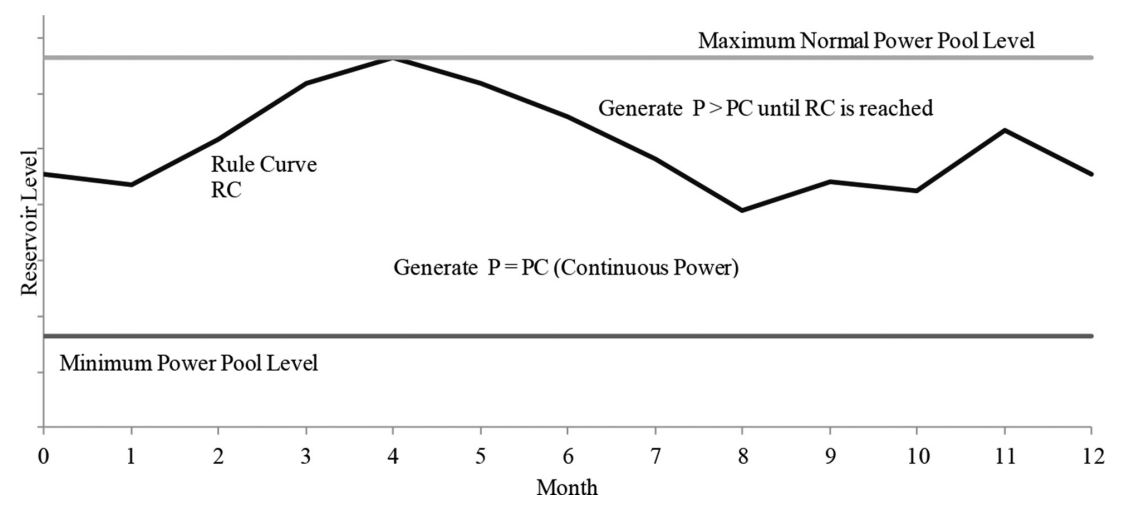

Figure 1: Typical USACE rule curve.

power pool level at any time. This backward simulation is repeated until the maximum continuous power/firm energy yield is obtained.

The Rule Curve is the envelope of the maximum end-of-month levels obtained in the backward simulation which gives the firm energy yield and continuous power. As a by-product of this procedure, at least one value of the Rule Curve is the top of the power pool. Figure 1 shows a typical rule curve (RC) for a reservoir following the USACE guidelines. It also shows the minimum and maximum pool levels, and the general recommendation for operation of the power plant. Under the USACE Rule Curve, the control of the reservoir operation depends only on the current time. There is no influence of the current state of the reservoir system in the selection of the value of the end-of-month control level, nor is there an explicit maximization of the mean energy generated by the reservoir.

Over the years, several researchers have proposed diverse methods to account for the influence of the state of the system over the value of the rule curve for the operation of reservoirs. Among those investigators working with single-plant reservoirs are Maher [2] and Alemu et al. [3]. Furthermore, Jaafar [4], includes an explicit algorithm for the maximization of the mean energy generated. Some of these works rely on extensive simulation studies to identify the rule curves (presuming a base form for the rule curve level, which is later modified) while others rely on optimization procedures applied to stochastic processes and develop the rule curves through curve-fitting procedures of the results.

In this approach, I propose a new development to generate an improvement for the Rule Curve stated in [1], to be used with the control strategy already stated in that same reference. The improvement is the inclusion of a parameter which represents the actual state of the reservoir system in the decision-making process, thus it becomes a 2-Parameter Rule Curve whose parameters are current time and reservoir level (at the beginning of the current month). The procedure to obtain the 2-Parameter Rule Curve is the following:

(a) The estimation of the value of a composite monthly parameter of the reservoir operation, $\mathrm{PT}=\Delta \mathrm{V}$ Hef, using the available hydrological data (inflow, rainfall, evaporation), for the generation of continuous power and firm energy; this composite parameter is a measure of the monthly maximum effective potential energy withdrawn from (negative values) or stored into the reservoir (positive values). The calculations are done with the same backwards simulation algorithm proposed in [1], with additional data processing at each time step to calculate the composite parameter $\Delta$ VHef. 
(b) At the end of the simulation, select the envelope of the maximum monthly values of the composite parameter, instead of the envelope of the maximum values of the end-ofmonth storage proposed in [1].

(c) The use of the composite monthly maximum parameter PTmax to estimate the end-ofmonth control reservoir levels. This task is done by solving the mass balance and net head equations with the appropriate efficiency, to give an end-of-month level to any given beginning-of-month reservoir level within the range of admissible levels in the reservoir power pool. Since the mass-balance equations involve the effective rainfall and evaporation over the reservoir surface, a conservative approach is the use of the minimum monthly values of the difference between the effective rainfall and effective evaporation, taken from the hydrological data set.

This procedure gives a one-to-one relationship between the initial reservoir level and the recommended final level for any month, as shown in Fig. 2.

For clarity purposes, Fig. 2 presents the year in four 3-month seasons. It shows the endof-month level as a function of the current month and the beginning-of-month level (as a percentage of the useful reservoir levels; $0 \%$ as the minimum power pool level and $100 \%$ as the maximum power pool level). The data can be presented in matrix form, with the required
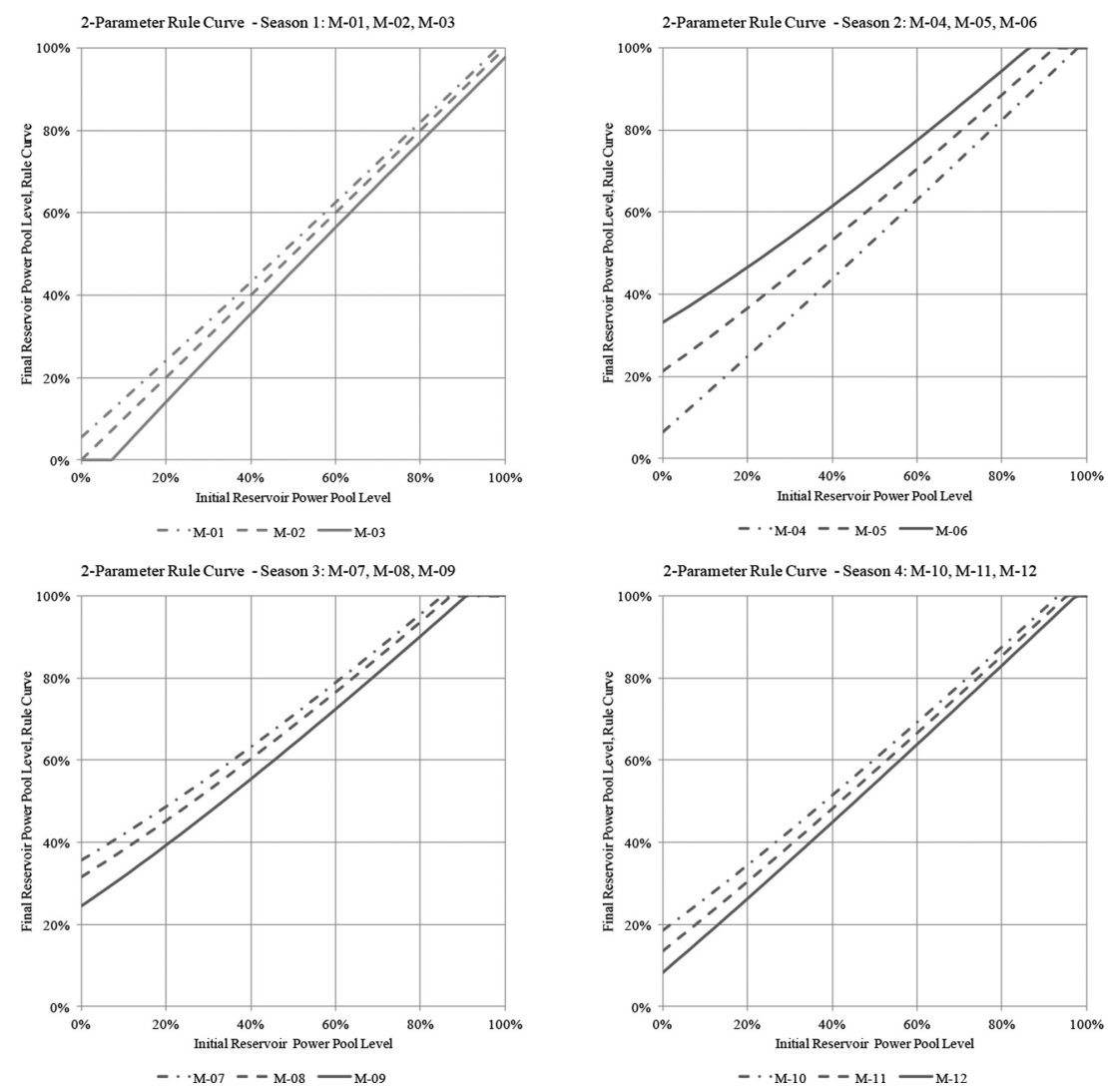

Figure 2: Typical 2-parameter rule curve. 
accuracy to perform interpolation between data points for any reservoir level (from minimum to maximum power pool levels).

The calculations are simple and straightforward in the derivation of the composite parameter and the estimation of the rule curve. There is no maximization algorithm, only the consideration of a parameter representative of the current state of the system. The use of this 2-Parameter Rule Curve with the control strategy presented in [1] can increase the annual energy output of the reservoirs while maintaining the firm energy yield. The increase in total energy can range from $2 \%-5 \%$ up to $20 \%-25 \%$ in some applications, depending on the characteristics of the reservoir and power-plant system, such as storage, rated capacity, net head variations and inflow.

\section{ESTIMATION OF THE 2-PARAMETER RULE CURVE}

This point contains the estimation of the 2-Parameter Rule Curve. First, there is the analytical description of the reservoir-power plant system, then, the estimation of the composite parameter which defines the Rule Curve, and, finally, the estimation of the 2-Parameter Reservoir Elevation Rule Curve.

\subsection{Description of the reservoir-power plant system}

The description of the system is the mass-balance equation of the reservoir, power output of the power plant, net head and efficiency of the turbines.

\subsubsection{Mass balance of reservoir}

The mass balance of the reservoir is represented by the following recursive equations, for any given period:

$$
\begin{gathered}
\mathrm{Vf}=\mathrm{Vi}+\Delta \mathrm{V} \\
\Delta \mathrm{V}=\operatorname{Qinf} \Delta \mathrm{T}-\mathrm{Qt} \Delta \mathrm{T}+(\mathrm{Kr} \mathrm{R}-\mathrm{Ke} \mathrm{Ev}) \text { Area } \\
-\mathrm{Qeco} \Delta \mathrm{T}-\mathrm{Q} \operatorname{loss} \Delta \mathrm{T}
\end{gathered}
$$

Subject to the inequality constrain:

$$
\mathrm{V} \min \leq \mathrm{Vf} \leq \mathrm{V} \max
$$

In which:

- Vf: Volume stored in the reservoir at the end of the month.

- Vi: Volume stored in the reservoir at the beginning of the month.

- $\Delta \mathrm{V}$ : Variation of volume stored in the reservoir during the period, without taking into account the restrictions imposed by the reservoir levels (maximum and minimum).

- Qinf: Average inflow into the reservoir during the current period.

- R: Total monthly rainfall over the reservoir area during the current period.

- Ev: Total monthly evaporation over the reservoir area during the current period.

- Qt: Average monthly flow into turbines during the current period.

- Qeco: Average ecological flow and other demands during the period which do not pass through the power house.

- Qloss: Average water losses during the period.

- Vmin: Volume stored at the minimum reservoir power pool level. 
- Vmax: Volume stored at the maximum reservoir power pool level.

- $\Delta \mathrm{T}$ : Time conversion factor from units of flow into monthly volume.

- Area: Average surface area of the reservoir during the period.

- Kr: Effective rainfall and conversion constant.

- Ke: Effective evaporation and conversion constant.

Notes:

1. The relationship between level-area-storage of the reservoir is represented by the levelarea-storage curve.

2. If the water surface level falls below the minimum power pool level, the reservoir cannot yield the required power and energy output, and the available water must be allocated to the diverse demands on a predefined priority basis. The final level is set to the minimum power pool level.

3. If the water level goes above the maximum power pool level, it generates a spill, which is then calculated. The final level is set to the maximum power pool level.

4. This procedure is repeated on a month-by-month basis, for the duration of the hydrological time series available.

2.1.2 Power output of power plant

The equations representing the power output of the power-plant are the following

$$
\begin{gathered}
\mathrm{P}=\gamma \mathrm{Qt} \mathrm{H} \eta \mathrm{t} \eta \mathrm{g} \\
\mathrm{E}=\mathrm{P} 24 \mathrm{Nd}
\end{gathered}
$$

Subject to the inequality constrains on the continuous power to generate firm energy:

$$
\mathrm{P} \geq \mathrm{CP}
$$

In which:

- P: Power output of the power-plant.

- CP: Continuous power.

- E: Total energy generated during period.

- $\gamma$ : Specific weight of water.

- Qt: Average water flow into the turbines during period.

- $\mathrm{H}$ : Average net head on the turbines during period.

- $\eta \mathrm{t}$ : Average efficiency of the turbine units during period.

- $\eta \mathrm{g}$ : Combined efficiency of the generator and transformer units.

- Nd: Number of days for the month.

\subsubsection{Net head}

The net head is a function of the reservoir elevation, the energy losses through the conveyance systems (free-surface and pressure flow) from the reservoir into the turbines, and the tailwater elevation rating, as follows:

$$
\mathrm{H}=\mathrm{Elev}-\mathrm{HL}-\mathrm{TW}
$$


In which:

- $\mathrm{H}$ : Average net head on the turbines during period.

- Elev: Average surface level of reservoir during period.

- HL: Average energy losses during the period, due to conveyance from reservoir into the power-plant. It is a function of total flow into the power-plant and unit flow into the turbines.

- TW: Average tailwater level during the period. It is a function of total flow into the power plant, and must take into account any spillway or other discharges that affect the power house discharge channel levels.

\subsubsection{Efficiency}

The efficiency of the turbines is a function of the net head and unit flow. The relationship between efficiency-head-flow is part of the data set and is read from the efficiency hill-diagrams of the turbines. The combined efficiency of the generator and transformer units is generally presumed constant.

\subsection{Estimation of the composite monthly parameter PT}

The backward simulation algorithm used to define the continuous power and firm energy can be represented by the equations:

$$
\begin{gathered}
\mathrm{Vi}=\mathrm{Vf}-\Delta \mathrm{V} \\
\mathrm{P}=\mathrm{CP}
\end{gathered}
$$

In which the variables are defined in eqns (1) and (2), with the initial condition of reservoir at minimum power pool level at the end of the time series. The equations are solved recursively backwards, beginning at the end of the time series, up to the initial period.

Once the continuous power and firm energy are identified by the backwards simulation procedure, the following parameter is calculated for the time-series:

$$
\mathrm{PT}(\mathrm{i}, \mathrm{j})=\Delta \mathrm{V}(\mathrm{i}, \mathrm{j}) \operatorname{HEF}(\mathrm{i}, \mathrm{j})
$$

In which:

- $\mathrm{i}, \mathrm{j}$ : indexes for the year and month of the time series.

- $\Delta \mathrm{V}(\mathrm{i}, \mathrm{j})$ : monthly value of the variation of storage during the period.

- $\operatorname{HEF}(\mathrm{i}, \mathrm{j})$ : monthly product of average net head and efficiency of the power-plant (turbines, generator and transformers combined).

2.2.1 Estimation of the variation in stored volume of reservoir

The calculation of $\Delta \mathrm{V}(\mathrm{i}, \mathrm{j})$ involves two variants, defined as: unrestricted variation (A10) and restricted variation (A20) of stored volume, as follows:

(a) Unrestricted variation of stored volume in reservoir, A10.

It is calculated, by eqn (2) before the imposition of the inequality constrains on the stored volume, as follows:

$$
\begin{gathered}
\Delta \mathrm{V}=\mathrm{Qinf} \Delta \mathrm{T}-\mathrm{Qt} \Delta \mathrm{T}+(\mathrm{Kr} \mathrm{R}-\mathrm{Ke} \mathrm{Ev}) \text { Area } \\
- \text { Qeco } \Delta \mathrm{T}-\operatorname{Qloss} \Delta \mathrm{T}
\end{gathered}
$$


(b) Restricted variation of stored volume in reservoir, A20:

It is calculated by the use of eqn (2) after the imposition of the inequality constrains on the stored volume at the beginning of the month:

$$
\begin{gathered}
\mathrm{Vmin} \leq \mathrm{Vi} \leq \mathrm{V} \max \\
\Delta \mathrm{V}=\mathrm{Vf}-\mathrm{Vi}
\end{gathered}
$$

If the inequality constrains are not binding, the two calculated values (unrestricted and restricted) are equal.

\subsubsection{Estimation of the average net effective head}

The net effective head is the product of net head and efficiency of the power-plant. The net head is defined in eqn (7), and the efficiency is a function of the net head and unit flow in the turbines.

$$
\begin{gathered}
\mathrm{H}=\mathrm{Elev}-\mathrm{HL}-\mathrm{TW} \\
\mathrm{HEF}=\mathrm{H} \eta \mathrm{t} \eta \mathrm{g}
\end{gathered}
$$

In which:

- HEF: Average net effective head.

- $\eta t$ : Efficiency of the turbines.

- $\eta g$ : Combined efficiency of the generators and transformers, presumed constant throughout the simulation.

2.2.3 Estimation of the end-of-month level for the 2-parameter elevation rule curve

The estimation of the end-of-month level proceeds after the maximum monthly values of the PT parameter are calculated. The calculations follow the inverse procedure to that which gave origin to the PT parameter and are described below for any given month or time period:

(a) Define initial reservoir levels

Any value ranging between the minimum and maximum power pool levels. To obtain the full range of end-of-month storage, the calculations must be repeated with initial level varying between the extremes, with the adequate variation to obtain a good definition of the curve.

(b) Define the extreme values of the effective rainfall and evaporation

The parameter $\operatorname{RE}(i, j)=+\operatorname{Kr} R(i, j)-\operatorname{Ke} \operatorname{Ev}(i, j)$ is the effective contribution of the rainfall and evaporation to the mass balance equation for year $\mathrm{i}$ and month $\mathrm{j}$. Use the time series available to estimate REmin(j), the minimum monthly value of this parameter to use in the mass-balance equations.

(c) Estimate the variation in storage to calculate the required end-of-month storage for all the initial reservoir levels required, considering the generation of continuous power and firm energy only. The equations used are, for any given month and initial reservoir level:

$$
\begin{aligned}
& \Delta \mathrm{V}=\mathrm{PTX} / \mathrm{HEF} \\
& \mathrm{Vf}=\mathrm{Vi}+\Delta \mathrm{V}-\mathrm{REmin} \text { Area }+ \text { Qeco } \Delta \mathrm{T}+\text { Qloss } \Delta \mathrm{T} \\
& \mathrm{V} \min \leq \mathrm{Vf} \leq \mathrm{V} \max
\end{aligned}
$$


In which:

- $\Delta \mathrm{V}$ : variation in storage from the beginning to end of month.

- PTX: maximum value of the PT parameter for the month.

- HEF: average effective net head for the period, considering the generation of continuous power and firm energy only.

- Vi: reservoir storage at the beginning of the month.

- Vf: reservoir storage at the end of the month.

- REmin: minimum value of the effective contribution of rainfall and evaporation, for the month.

- Area: average surface area of the reservoir during the period.

The calculations require the use of the net head and power equations already defined.

(d) Determine the end-of-month level for the Rule Curve

Once the storage at the end of the month is calculated, use the level-area-storage curve to estimate the reservoir level that defines de Elevation Rule Curve.

\section{COMBINATION OF THE 2-PARAMETER AND USACE RULE CURVES}

The principal purpose of the Elevation Rule Curves is to preserve the Firm Energy yield of the reservoir. Both elevation rule curves present a recommended end-of-month storage based on the current time of year, and for the 2-Parameter Rule Curve, also on the reservoir level at the beginning of the month. Figure 3 shows a typical 2-Parameter and USACE Rule Curves for the same month and reservoir, ranging from the minimum to the maximum power

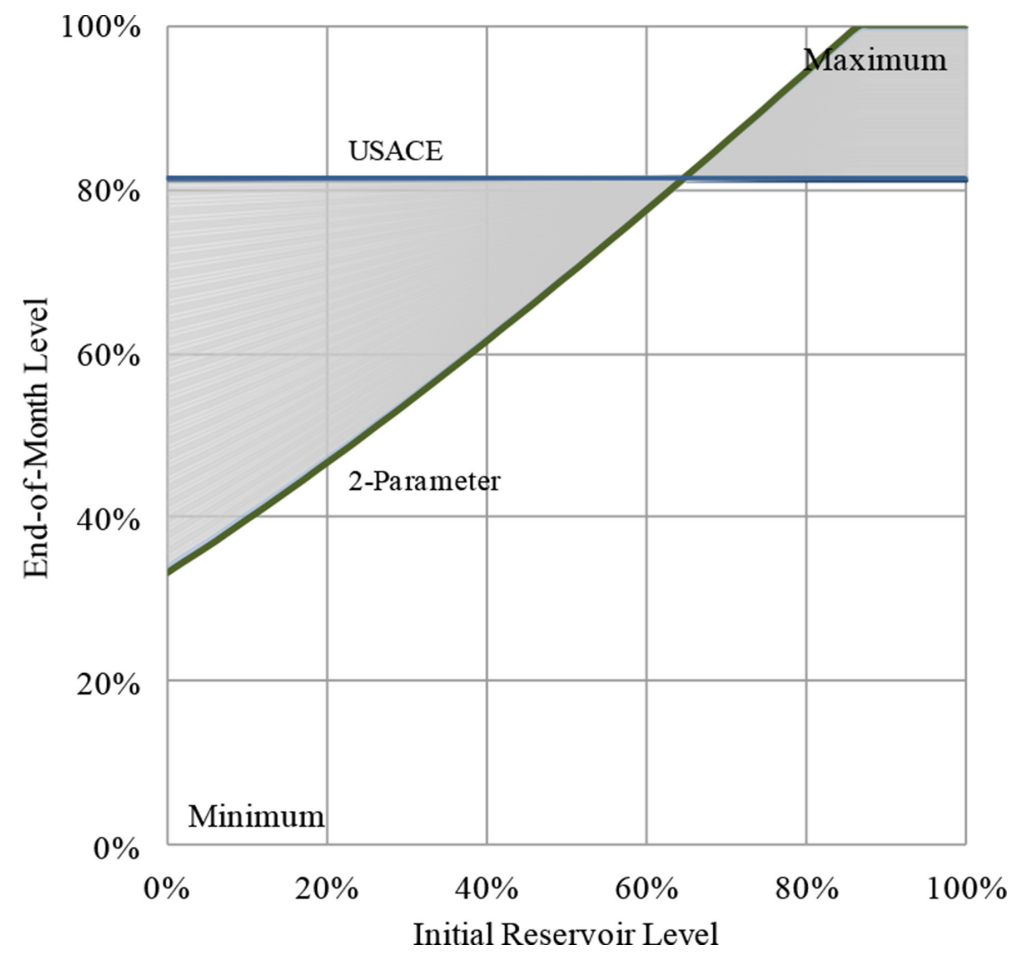

Figure 3: Typical 2-parameter and USACE rule curves, for one month. 
pool levels. The 2-Parameter Rule Curve presents the end-of-month level as a function of the beginning-of-month level, whereas the USACE Rule Curve is a constant value.

The region between the two Rule Curves (shaded) is a complementary solution space for a Rule Curve, which can be explored methodically by a linear combination of the level/storage and the extreme values of the curves. The best combination can then be selected by simulation and evaluation of results.

\subsection{Linear combination}

The Linear Combination Rule Curve of the level/storage is represented by any of the following equations:

(a) Linear Combination on Level

$$
\mathrm{LC}=\mathrm{w} \mathrm{L} 2-\mathrm{P}+(1-\mathrm{w}) \text { LUSACE }
$$

(b) Linear Combination on Storage

$$
\mathrm{SC}=\mathrm{w} \mathrm{S} 2-\mathrm{P}+(1-\mathrm{w}) \mathrm{SUSACE}
$$

The Combined Rule Curve level, LC, is then interpolated from the elevation-area-storage curve.

In which:

- LC: Combined Rule Curve Level.

- L2-P: 2-Parameter Rule Curve Level.

- LUSACE: USACE Rule Curve Level.

- SC: Combined Rule Curve Storage.

- S2-P: 2-Parameter Rule Curve Storage.

- SUSACE: USACE Rule Curve Storage.

- w: weight assigned to the 2-Parameter Rule Curve in the linear combination, it lies within the normalized range from 0 to 1 . The weight can be the same throughout the year, or can vary with the month-seasons.

Note that a linear combination on level is different than a linear combination on storage due to the nonlinearity of the level-area-storage curve of the reservoirs as shown in Fig. 4.

a) Linear Combination on Level

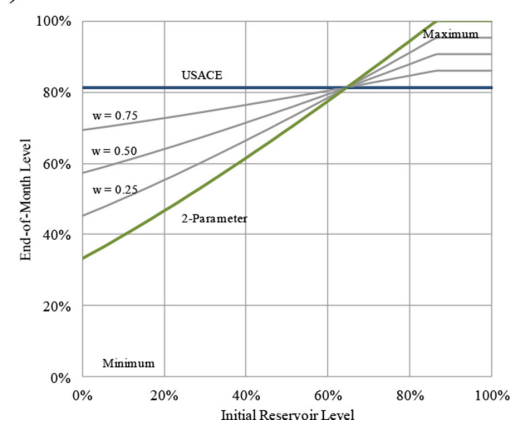

b) Linear Combination on Volume

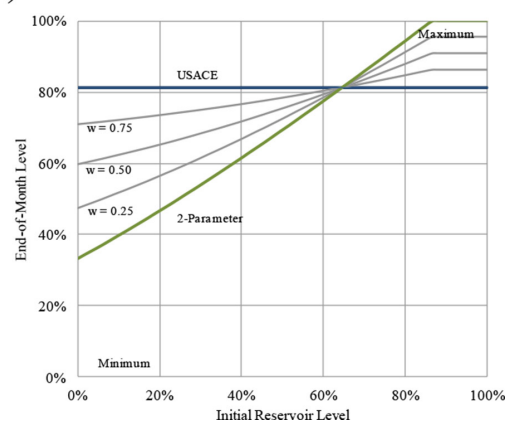

Figure 4: Typical linear combination of level and volume. 
a) Maximum Values

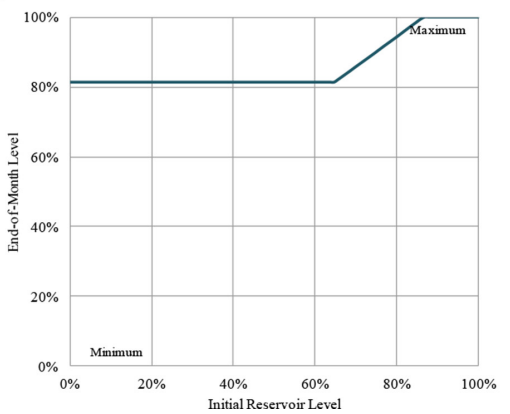

b) Minimum Values

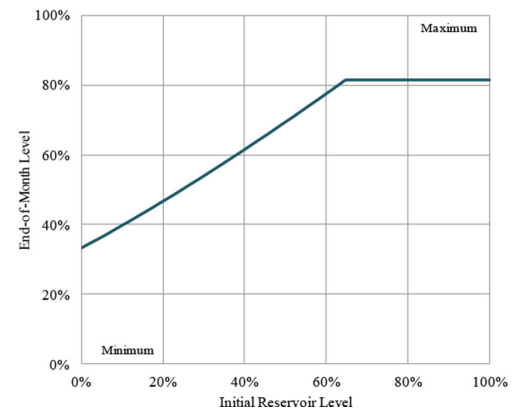

Figure 5: Combination of maximum/minimum levels.

\subsection{Extreme values}

This combined Extreme Value Rule Curve is represented by any of the following equations:

(a) Maximum Value

$$
\text { LC }=\max (\text { L2-P, LUSACE) }
$$

(b) Minimum Value

$$
\mathrm{LC}=\min (\mathrm{L} 2-\mathrm{P}, \text { LUSACE})
$$

In which:

- LC: Combined Rule Curve Level.

- L2-P: Level of the 2-Parameter Rule Curve.

- LUSACE: Level of the USACE Rule Curve.

\section{APPLICATION TO GRAND COULEE DAM}

As an example of the application of the 2-Parameter Rule Curve, I chose Grand Coulee Dam, in the United States, due to the availability of the required data to run the simulations and the data furnished by the USBR on the operation of the dam. The hydrological time-series is presented in reference [5], the level-area-storage curve in reference [6] and the tailwater level in reference [7]. The data on reservoir levels and powerplant capacity have been taken from the site www.usbr.gov.

4.1 Reservoir data and power plant data and operations

The basic reservoir and power plant data are presented in Table 1.

\subsection{Data for simulation of power plant}

To simulate the turbines, the nominal head was estimated with the reservoir level at the centre of mass of the useful storage. The conveyance losses were assumed constant equal to $1.5 \mathrm{~m}$. The combined efficiency of the generators and transformers was assumed 0.96 constant. To 
Table 1: Grand coulee dam data.

\begin{tabular}{|c|c|c|c|}
\hline \multicolumn{2}{|l|}{ Hydrology and reservoir } & \multicolumn{2}{|l|}{ Power plant } \\
\hline $\begin{array}{l}\text { Maximum power pool } \\
\text { level }\end{array}$ & $\begin{array}{l}1,290 \mathrm{ft} \\
393.2 \mathrm{masl}\end{array}$ & Number of turbines & 24 \\
\hline $\begin{array}{l}\text { Minimum power pool } \\
\text { level }\end{array}$ & $\begin{array}{l}1,208 \mathrm{ft} \\
368.2 \mathrm{masl}\end{array}$ & Type of turbines & Francis \\
\hline Useful storage & $\begin{array}{l}5,185,000 \mathrm{AF} \\
6,400 \text { mill. } \mathrm{m} 3\end{array}$ & Rated Capacity & 6,494 MW \\
\hline Tailwater level & $\begin{array}{l}952 \mathrm{ft} \\
290.2 \text { masl }\end{array}$ & $\begin{array}{l}\text { Mean annual power } \\
\text { output } \\
\text { (Reported USBR) }\end{array}$ & $21 \mathrm{TW}-\mathrm{h}$ \\
\hline Inflow & $3,080 \mathrm{~m} 3 / \mathrm{s}$ & & \\
\hline
\end{tabular}

simulate the efficiency of the turbines, I selected the hill-diagram of a Francis turbine with a specific speed of 334 (metric units) adequate for the estimated head in the range of 80-85 m, presented in reference [8].

\subsection{Simulation results}

The operation of Grand Coulee dam was simulated with varying power plant capacities, ranging from 3,000 MW up to 8,000 MW, to cover the actual rated capacity of 6,500 MW. The simulated energy generated and average head are shown in Figs 6-8, using the USACE Rule Curve and the 2-Parameter Rule Curve in all its combinations. In case of linear combination of 2-Parameter and USACE Rule Curves, the weight assigned to the 2-Parameter Rule

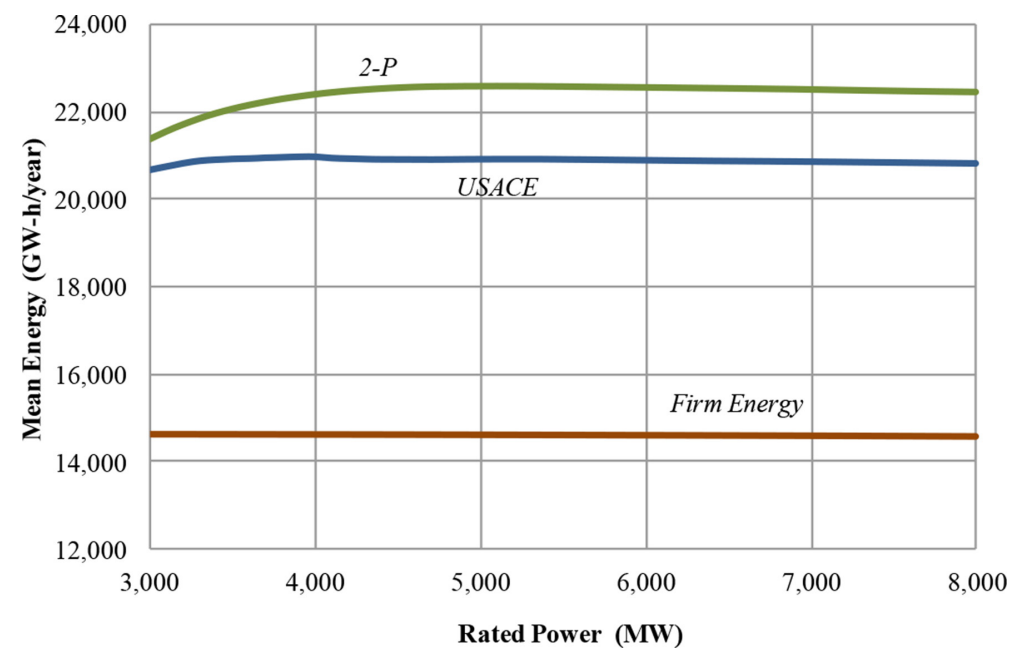

Figure 6: Firm energy and mean annual total energy generated by the use of the USACE and 2-parameter rule curves. 


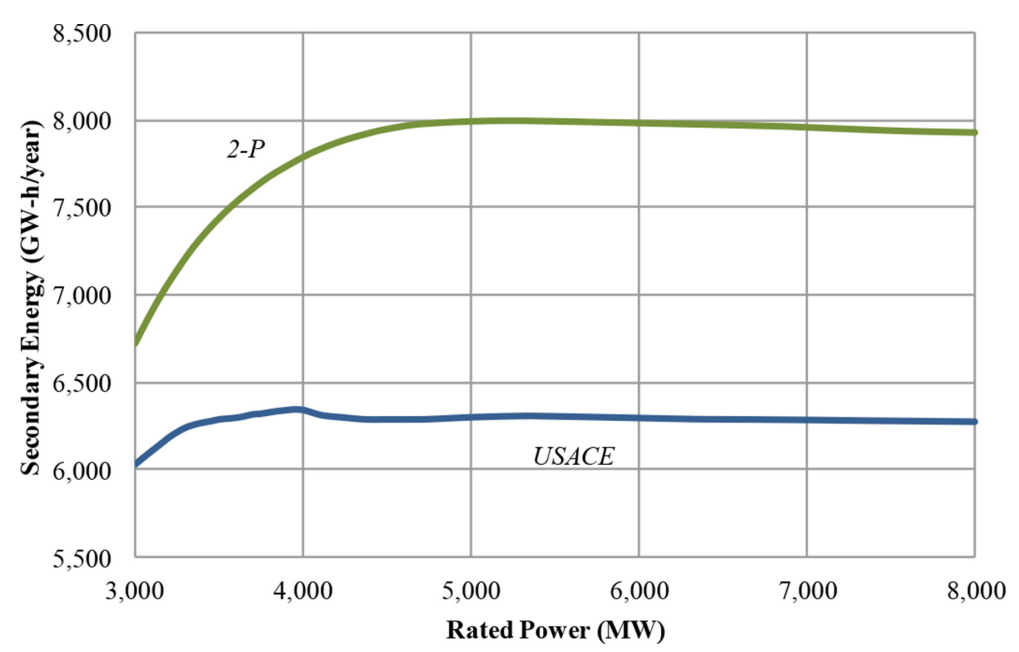

Figure 7: Mean annual secondary energy generated by the use of the USACE and 2-parameter rule curves.

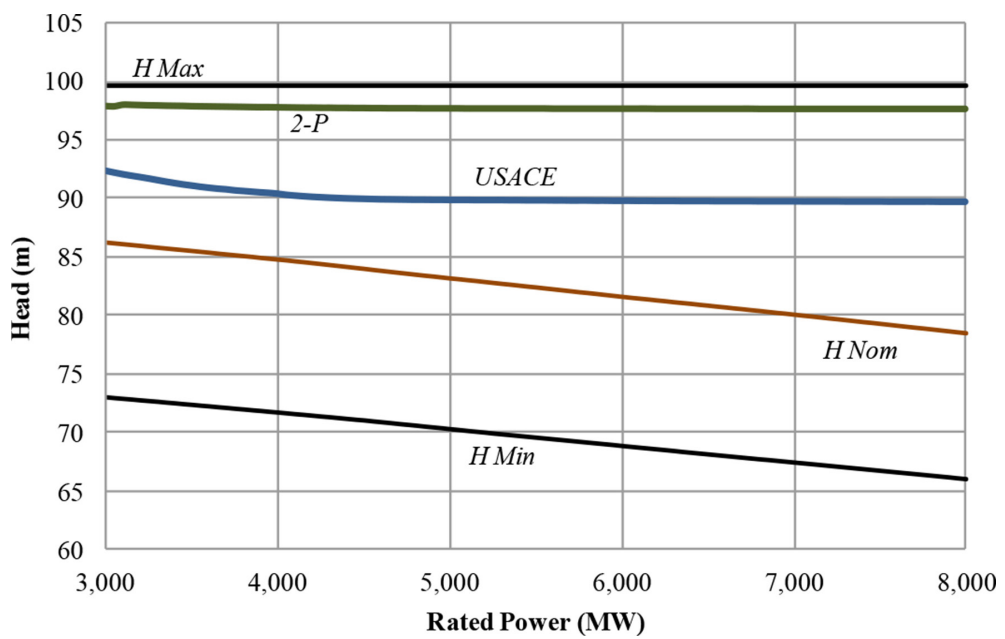

Figure 8: Energy-averaged mean head, nominal, maximum and minimum head.

Curve varied from 0.05 to 0.95 , was the same for every month of the year. The data presented for the results of the 2-Parameter Rule Curve corresponds to the maximum mean energy generated.

Figure 6 shows the Mean Annual Energy and Firm Energy Yield. The firm energy is 14.6 TW-h. The energy generated with a rated capacity of 6,500 MW is $20.9 \mathrm{TW}-\mathrm{h}$ with the USACE Rule Curve, close to the reported output $21 \mathrm{TW}-\mathrm{h}$. The energy output is $22.6 \mathrm{TW}-\mathrm{h}$ by the use of the 2-Parameter Rule Curve. The increase of $1.7 \mathrm{TW}-\mathrm{h}$ is due only to the change of the Rule Curve.

Figure 7 shows the Secondary Energy, in the range from 6 TW-h to 8 TW-h. The Secondary energy increases from $6.3 \mathrm{TW}$-h to $8.0 \mathrm{TW}$-h. 
Figure 8 shows the energy-averaged head, along with the nominal, maximum and minimum head. It shows the increase in average head, from $90 \mathrm{~m}$ using the USACE Rule Curve to $98 \mathrm{~m}$ by the use of the 2-Parameter Rule Curve.

Table 2 shows the mean annual energy generated for several rated capacities, Table 3 presents the secondary annual energy and Table 4 presents the energy-averaged head for the same rated capacities.

Table 2: Mean annual energy generated with USACE and 2-P Rule Curves.

\begin{tabular}{lccccc}
\hline \multirow{2}{*}{$\begin{array}{l}\text { Rated } \\
\text { capacity } \\
(\mathrm{MW})\end{array}$} & $\begin{array}{c}\text { Firm energy } \\
(\text { TW-h) }\end{array}$ & USACE & $2-\mathrm{P}$ & $(\mathrm{TW}-\mathrm{h})$ & $(\%)$ \\
\cline { 3 - 6 } & 14.6 & 21.0 & 22.4 & +1.4 & +6.9 \\
4,000 & 14.6 & 20.9 & 22.6 & +1.7 & +8.0 \\
5,000 & 14.6 & 20.9 & 22.6 & +1.7 & +8.0 \\
6,000 & 14.6 & 20.9 & 22.6 & +1.7 & +8.0 \\
6,500 & & & & & \\
$($ actual $)$ & 14.6 & 20.9 & 22.5 & +1.7 & +8.0 \\
7,000 & 14.6 & 20.8 & 22.5 & +1.7 & +7.9 \\
8,000 & & & & &
\end{tabular}

Table 3: Secondary annual energy generated with USACE and 2-P rule curves.

\begin{tabular}{llllll}
\hline \multirow{2}{*}{$\begin{array}{l}\text { Rated capacity } \\
(\mathrm{MW})\end{array}$} & $\begin{array}{l}\text { Firm energy } \\
(\mathrm{TW}-\mathrm{h})\end{array}$ & \multicolumn{2}{l}{ Secondary energy (TW-h) } & \multicolumn{2}{l}{ Energy change } \\
\cline { 3 - 6 } & USACE & $2-\mathrm{P}$ & $(\mathrm{TW}-\mathrm{h})$ & $(\%)$ \\
\hline 4,000 & 14.6 & 6.3 & 7.8 & +1.4 & +22.7 \\
5,000 & 14.6 & 6.3 & 8.0 & +1.7 & +26.7 \\
6,000 & 14.6 & 6.3 & 8.0 & +1.7 & +26.7 \\
6,500 & 14.6 & 6.3 & 8.0 & +1.7 & +26.6 \\
$($ actual) & & & & & +1.7 \\
7,000 & 14.6 & 6.3 & 8.0 & +1.7 & +26.5 \\
8,000 & 14.6 & 6.3 & 7.9 & +26.2 \\
\hline
\end{tabular}

Table 4: Energy-averaged head with USACE and 2-P rule curves.

\begin{tabular}{lccccc}
\hline \multirow{2}{*}{$\begin{array}{l}\text { Rated capacity } \\
(\mathrm{MW})\end{array}$} & $\begin{array}{c}\text { Firm energy } \\
(\text { TW-h) }\end{array}$ & \multicolumn{2}{c}{ USACE } & $2-\mathrm{P}$ & \multicolumn{2}{c}{ Head change } \\
\cline { 3 - 6 } & 14.6 & 90.4 & 97.8 & 7.4 & 8.2 \\
5,000 & 14.6 & 89.8 & 97.7 & 7.9 & 8.8 \\
6,000 & 14.6 & 89.7 & 97.6 & 7.9 & 8.8 \\
6,000 & 14.6 & 89.7 & 97.6 & 7.9 & 8.9 \\
(actual) & & & & & \\
7,000 & 14.6 & 89.7 & 97.6 & 8.0 & 8.9 \\
8,000 & 14.6 & 89.6 & 97.6 & 8.0 & 8.9 \\
\hline
\end{tabular}


The comparison of the data presented in Tables 2 and 4, shows that the increase in mean annual energy is around $8 \%$, similar to the increase in average net head, around $9 \%$. This shows that the energy increase is mainly due to the increase in net head, and reservoir levels, due to the change of the Rule Curve.

\section{CLOSING REMARKS}

The use of the newly developed 2-Parameter Elevation Rule Curve for hydropower generation can increase mean energy output without compromising the firm energy yield. The energy increase is related to the increase in reservoir levels, and net head. The 2-Parameter Elevation Rule Curve can be used as a stand-alone or in combinations with the USACE Rule Curve; and the best combination can be selected by simulation.

The only change in real-time operation is the end-of-month control level/volume used by the operators to control the release and energy output. There is no change in infrastructure and can be applied to existing reservoirs as well as those under study.

\section{REFERENCES}

[1] Department of the Army, US Army Corps of Engineers (USACE), Engineering Manual $\mathrm{N}^{\circ}$ 1110-2-1701, "Engineering and Design, Hydropower", 31 Dec 1985 and 5 June 1989.

[2] Maher, K.M., Potential Use of Real-time Information for Flood Operation Rules for Folsom Reservoir, MSc Thesis, University of California, Davis, 2011.

[3] Alemu, E.T., Palmer, R.N., Polebitski, A. \& Meaker, B., Decision support system for optimizing reservoir operations using ensemble streamflow predictions. Journal of Water Resources Planning and Management, American Society of Civil Engineers, Jan/ Feb 2011.

[4] Jaafar, H.H., Maximizing hydropower production from reservoirs: the case study of markaba. Lebanese Science Journal, 15, (2), 2014.

[5] Columbia River Mainstem Storage Options, Off-Channel Storage Assessment PreAppraisal Report, prepared for the U.S. Bureau of Reclamation by MWH, Dec 2005.

[6] U.S. Bureau of Reclamation, Technical Report No. SRH-2012-06: "Franklin D. Roosevelt Lake - Grand Coulee Dam 2010-11 Survey”, June 2012, prepared by Donald L. Ferrari.

[7] Dozier, A., Integrated Water and Power Modeling Framework for Renewable Energy Integration, MSc Thesis, Colorado State University, 2012.

[8] U.S. Department of the Interior, Bureau of Reclamation, a Water Resources Technical Publication, Engineering Monograph $N^{\circ} 20$, Selecting Hydraulic Reaction Turbines, 1976. 